\title{
A REMUNERAÇÃO VARIÁVEL COMO SUPORTE ÀS ESTRATÉGIAS ORGANIZACIONAIS: O CASO DAS PRIMIUM PARTNER XEROX NO MERCADO BRASILEIRO
}

\section{VARIABLE REMUNERATION AS SUPPORT TO THE ORGANIZATIONAL STRATEGIES: THE CASE OF XEROX PRIMIUM PARTNER IN THE BRAZILIAN MARKET}

\author{
Ademar Dutra ${ }^{1}$; Mauro Rodrigues ${ }^{2}$; Fernando Antonio Ribeiro Serra ${ }^{3}$; Maurício Vasconcellos Leão \\ Lyrio $^{4}$ \\ ${ }^{1}$ Doutor / Professor e Pesquisador da Universidade do Sul de Santa Catarina - UNISUL - \\ Florianópolis - SC \\ ademar.dutra@unisul.br \\ ${ }^{2}$ Mestre / Universidade do Sul de Santa Catarina - Florianópolis - SC \\ mauro.rodrigues@xbramar.com.br \\ ${ }^{3}$ Doutor / Professor e Pesquisador da HSM Educação - São Paulo - SP \\ fernandoserra@hsm.com.br \\ ${ }^{4}$ Mestre / Professor e Pesquisador da ÚNICA / SOCIESC - Florianópolis - SC \\ mauriciovll@gmail.com
}

\section{Resumo:}

A partir dos anos 90, muitas organizações iniciaram a reestruturação e a transformação das culturas do trabalho remodelando suas estratégias de remuneração na busca de vantagem competitiva nos setores em que atuam. O presente trabalho se insere neste contexto, buscando responder à seguinte questão: Quais são as estratégias organizacionais cujo alcance pode ser alavancado por meio da implantação e manutenção de um Sistema de Remuneração Variável (SRV)? Tem por objetivo analisar como o SRV nas empresas Primium Partner Xerox é capaz de promover a criação de diferenciais competitivos para estas empresas frente ao mercado em que atuam. Trata-se de uma pesquisa de caráter exploratório e descritivo, realizada por meio de um estudo multicasos. A amostra é composta por 12 (doze) empresas que responderam ao questionário proposto, sendo que os dados utilizados são primários, levantados junto aos diretores das empresas respondentes. Como resultados, constatou-se que (i) o impacto do SRV nas estratégias organizacionais se dá naquelas relacionadas às pessoas, principalmente na retenção de talentos na organização; e, (ii) os diferenciais competitivos alavancados pelo SRV estão ligados à melhoria da qualidade no atendimento técnico oferecido pelos funcionários e ao comprometimento da equipe com os resultados da organização.

Palavras-chave: Estratégia; Remuneração Estratégica; Sistema de Remuneração Variável. 


\section{Introdução}

As mudanças no mundo do trabalho, resultantes da inserção da economia brasileira no processo de globalização, principalmente a partir da década de 90, apresentou impactos expressivos para as organizações diante de pressões competitivas crescentes. A competitividade exigiu das empresas investimentos em modernização, a implantação de novos modelos de gestão e principalmente, estratégias de mobilização e comprometimento de seus colaboradores.

Segundo Flannery, Hofrichter e Platten (1997), embora cada setor se encontre passando por um conjunto específico de mudanças, há 06 (seis) mudanças que são comuns a quase todas as empresas, são elas: (i) tecnologias em rápida expansão; (ii) concorrência global crescente; (iii) demanda crescente por competências e capacidades individuas e empresariais; (iv) maiores expectativas dos clientes; (v) ciclos cada vez mais curtos; (vi) mudanças nos requisitos pessoais.

Neste novo cenário a tecnologia aplicada substitui os trabalhos operacionais e rotineiros evidenciando cada vez mais que as organizações têm seu valor agregado vinculado ao conhecimento e criatividade que acrescentam, ao invés da força muscular de seus funcionários. $\mathrm{O}$ valor que essas pessoas adicionam a uma empresa depende diretamente de suas habilidades e conhecimentos e dos sistemas de recompensas adotados. À medida que os colaboradores adquirem mais habilidades, eles se tornam recursos mais flexíveis, capazes de desempenhar múltiplos papéis, desenvolver uma compreensão mais ampla dos processos de trabalho e, desta forma, obter uma compreensão melhor da importância de sua contribuição para a organização.

Apesar de a grande maioria das empresas ainda aplicar exclusivamente sistemas tradicionais de remuneração, baseados nas descrições de atividades e responsabilidades de cada função (PICARELLI, 1999), muitas organizações, a partir da década de 90, iniciaram a reestruturação e a transformação de suas culturas, e decidiram - temerosas com o que tem sido chamado de o desafio de recursos humanos nas organizações - remodelar suas estratégias de remuneração, na busca de vantagem competitiva no setor em que atua.

O presente artigo se insere neste contexto, buscando analisar a relação entre as práticas de remuneração variável com as estratégias organizacionais nas empresas Primium Partner Xerox. Para tanto, busca responder à seguinte Pergunta de Pesquisa (PP): Quais são as estratégias organizacionais cujo alcance pode ser alavancado por meio da implantação e manutenção de um Sistemas de Remuneração Variável?

Para atingir o objetivo principal, os seguintes objetivos específicos serão perseguidos: (i) identificar e analisar as práticas de gestão adotadas pelas empresas em estudo, a partir do uso de Sistemas de Remuneração Variável (SRV); (ii) identificar e analisar os fatores bloqueadores e facilitadores inerentes à implantação e utilização do sistema de remuneração variável nestas 
organizações; e, (iii) identificar e analisar quais são os diferenciais competitivos que sofrem impacto do SRV adotado pela organização.

A escolha pelas empresas Primium Partner Xerox que atuam no mercado nacional como objeto deste estudo deu-se devido a recente iniciativa da Multinacional Xerox do Brasil S/A em terceirizar suas atividades de acordo com estruturas globais já existentes, fato este que determinou a estas empresas buscarem imediatas alternativas que pudessem criar um diferencial às suas equipes frente ao mercado em que atuam.

A importância desta pesquisa pode ser confirmada pela sua contribuição nos seguintes aspectos: (i) o impacto dos sistemas de remuneração na manutenção e retenção do capital intelectual nas organizações tem sido motivo de diversos estudos no meio acadêmico, a partir de diferentes perspectivas, no entanto, por meio de uma análise da literatura realizada na base de dados Web of Science (ISI) e nos anais do Encontro da ANPAD não se identificou estudos com o objetivo de analisar como o sistema de remuneração variável ajuda a alavancar a estratégia organizacional; e (ii) evidenciar de forma prática a contribuição do sistema de remuneração variáveis e seu impacto nas estratégias organizacionais.

O trabalho é organizado da seguinte forma: após esta introdução a seção 2 - Plataforma teórica - trata do referencial utilizado no desenvolvimento do estudo envolvendo: (i) estratégia como um diferencial competitivo; (ii) a integração da gestão de pessoas com a estratégia organizacional; e, (iii) remuneração como um fator estratégico. Em seguida a seção 3 - Metodologia da Pesquisa trata (i) do enquadramento metodológico da pesquisa; (ii) dos procedimentos metodológicos utilizados na pesquisa; e, (iii) da aplicação da pesquisa. A seção 4 - Apresentação e Análise dos Resultados - trata (i) da apresentação das organizações Primium Partner Xerox; (ii) da análise dos resultados envolvendo a estrutura do SRV, o impacto do SRV nas estratégias organizacionais e os aspectos relacionados à implantação do SRV; e, (iii) trata da análise dos resultados frente aos fundamentos teóricos apresentados. Por fim, a seção 5 - Conclusões e recomendações - apresenta a discussão final sobre o tema e as recomendações para trabalhos futuros.

\section{Plataforma Teórica}

Deve-se levar em consideração, na fundamentação teórica do presente estudo, o caráter dinâmico do tema remuneração variável nas organizações, uma vez que existem variáveis diretas e indiretas que afetam tais organizações, além do fato de interesses pessoais sobrepujarem os interesses coletivos em muitos casos. Dado este entendimento esta seção buscará focar a discussão nos aspectos relacionados especificamente à estratégia e a relação desta com a gestão de pessoas e a forma de remuneração adotada pela organização, envolvendo: (i) estratégia como um diferencial 
competitivo; (ii) a integração da gestão de pessoas com a estratégia organizacional; (iii) a remuneração como um fator estratégico; e, (iv) pesquisas anteriores com enfoque similar.

\subsection{Estratégia como um Diferencial Competitivo}

Segundo Mintzberg (2001), a organização consiste de estrutura, processos que cortam as linhas estruturais como preparação de orçamentos, planejamento, equipes e assim por diante, sistemas de premiação como promoções e salários, e finalmente, práticas como seleção e desenvolvimento (

Figura 1).

Figura 1 - Modelo de Estrutura Organizacional

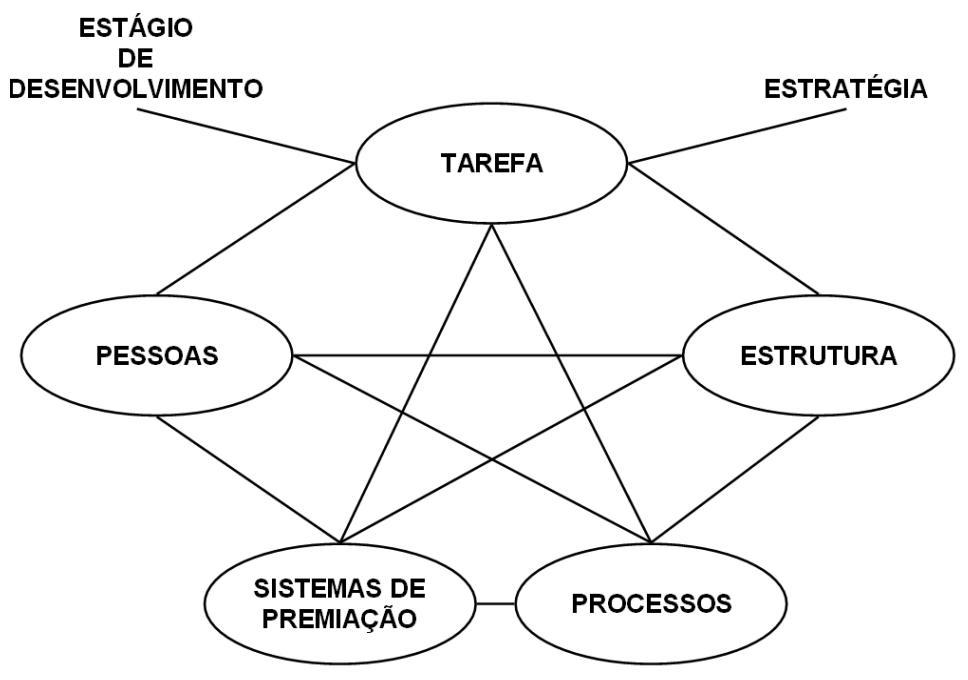

Fonte: Mintzberg e Quinn, 2001 p. 133

Todos esses atributos têm como finalidade transmitir as mesmas idéias. Primeiro que a organização é mais do que simples estrutura. Segundo, todos os elementos precisam se encaixar para estar em harmonia entre si. A organização eficiente é aquela que mesclou a sua estrutura, práticas gerenciais, recompensas e pessoas em um único pacote que, por seu turno, ajusta-se com uma estratégia. Entretanto, estratégias mudam e, portanto, as organizações precisam mudar.

Segundo Porter (1990), a essência da formulação de uma estratégia competitiva é relacionar uma companhia ao seu meio ambiente. Embora o meio ambiente relevante seja muito amplo, abrangendo tanto forças sociais como econômicas, o aspecto principal do meio ambiente da empresa é a indústria ou as indústrias em que ela compete. A intensidade da concorrência em uma indústria não é uma questão de coincidência ou de má sorte. Ao contrário, a concorrência em uma indústria tem raízes em sua estrutura econômica básica e vai além do comportamento dos atuais concorrentes. 
A meta da estratégia competitiva para uma unidade empresarial em uma indústria é encontrar uma posição dentro dela em que a companhia possa melhor se defender contra estas forças competitivas ou influenciá-las em seu favor. Dado que o conjunto das forças pode estar exageradamente aparente para todos os concorrentes, a chave para o desenvolvimento de uma estratégia é pesquisar em maior profundidade e analisar as fontes de cada força.

Para que a organização encontre um posicionamento no setor em que atua por meio da utilização de alguma estratégia competitiva é necessário que esta organização tenha pessoas adequadas à estrutura organizacional e preparadas para realizar os processos. Dentro desse entendimento, a estratégia organizacional passa, inevitavelmente pela gestão de pessoas, assunto tratado a seguir.

\subsection{A Integração da Gestão de Pessoas com a Estratégia Organizacional}

A administração estratégica é um processo amplo que permite à organização procurar atingir o seu propósito ao longo do tempo. Esse processo abrange a visão, a formulação e a implementação, bem como o feedback contínuo e a avaliação dos resultados, tendo em vista orientar e empreender as ações organizacionais de natureza estratégica, tática e operacional (ALBUQUERQUE, 1999).

Goldsmith (1997) comenta que os líderes das organizações já não podem permitir que os caprichos do mercado de trabalho determinassem quem sai e quem fica na empresa. Segundo o autor (Ibid.) devemos aprender a gerir nossos ativos humanos com o mesmo rigor devotado aos nossos ativos financeiros, seguindo 07 (sete) etapas fundamentais neste processo: (i) Identificar com clareza os funcionários que devem ser mantidos na empresa; (ii) Deixar que os funcionários saibam que a empresa deseja retê-los; (iii) Demonstrar reconhecimento; (iv) Oferecer oportunidades de desenvolvimento e envolvimento; (v) Desafiar o plano de remuneração; (vi) Ser mais flexível com as tradições da empresa; e, (vii) Oferecer ao empregado oportunidades de ação empreendedora.

No passado, quando um funcionário de alto desempenho de uma empresa recebia oferta de um cargo em outra empresa, era mais certo que não aceitasse o convite. A maioria dos cargos administrativos e técnicos oferecia bons salários, estabilidade no emprego e a possibilidade de ascensão profissional e social. Hoje, o funcionário altamente conceituado está inclinado a responder “sim”. No futuro, para reter tal talento as organizações terão de claramente identificar, desenvolver, envolver e reconhecer funcionários-chave. Os planos de remuneração tradicionais devem ser desafiados, a burocracia eliminada, e oportunidades de desenvolvimento da ação empreendedora nas organizações devem ser oferecidas.

As organizações incapazes de modificar seus sistemas de recursos humanos para atender às realidades do futuro perderão vantagem competitiva. Aquelas que conseguirem criar um modelo 
novo e dinâmico de recursos humanos irão segurar os talentos altamente qualificados, necessários para o sucesso do futuro ambiente de competição global.

Segundo Albuquerque (1999) as organizações utilizam informações do ambiente para formular suas estratégias corporativas e de recursos humanos. A importância de analisar as tendências de mudanças do ambiente econômico, tecnológico, social, cultural e político e seus impactos sobre a organização e sua gestão é ressaltada na própria conceitualização de estratégia, esta, ao mesmo tempo, emergindo como resposta aos desafios ambientais.

Em um ambiente turbulento, como o que tem caracterizado os dias atuais, em que o tempo se torna um recurso estratégico e a velocidade a nova palavra de ordem, monitorar continuamente o ambiente e assumir atitudes proativas em relação às mudanças, revendo cenários e reformulando estratégias, é fundamental para a maioria das organizações.

As organizações, portanto, formulam estratégias lidando com seu ambiente. Anthony et. al. (1996) consideram o ambiente de recursos humanos multifacetado e complexo, com muitos elementos impactantes sobre o processo de uma empresa à longo prazo. Nesse sentido torna-se adequado integrar a gestão dos recursos humanos da organização à estratégia da mesma. Entre os fatores que potencialmente podem apoiar esse processo de integração está a remuneração, que se utilizada de forma a ajudar a desenvolver as habilidades requeridas das pessoas, acaba por tornar-se um fator estratégico que apoiará a organização na busca de seus objetivos de longo prazo.

\subsection{Remuneração Como um Fator Estratégico}

Segundo o professor norte-americano Edward E. Lawler II, o problema central é que os sistemas de remuneração em uso foram criados para um tipo de empresa que está em extinção.

As profundas transformações que as empresas vem sofrendo exigem novos sistemas de remuneração. Em ambientes caracterizados por formas modernas de organização do trabalho como celularização, multifuncionalidade e poucos níveis hierárquicos - não faz sentido recompensar a contribuição individual ou coletiva apenas com base em descrições de atividades e definição de responsabilidades.

Então, a questão central é transformar a visão usual da remuneração como fator de custo para uma visão da remuneração como fator de aperfeiçoamento da organização, impulsionador de melhoria e aumento de competitividade.

Wood e Picarelli (1996), definem a remuneração estratégica como uma forma de ligação com a realidade, um vínculo com a nova realidade das organizações que atuam num mercado globalizado e competitivo. E esse vínculo se dá de duas maneiras: 
- Primeiro, no sentido de considerar todo o contexto organizacional, ou seja, de levar em conta as grandes categorias que dão forma e conteúdo à empresa: a estratégia, a estrutura e o estilo gerencial. A concepção de um sistema de remuneração estratégica deve partir do que a empresa é hoje e do que ela deseja ser amanhã (sua visão de futuro);

- Segundo, no sentido de que os indivíduos passam a ser remunerados de forma a refletir todo o conjunto de fatores que afetam sua contribuição para o sucesso do negócio: suas características pessoais, as características do cargo e o vínculo com a organização. Assim, além das atribuições e responsabilidades, outros aspectos devem ser considerados ao se projetar um sistema de remuneração: conhecimentos, habilidades, desempenho, resultados, evolução da carreira e competências.

A remuneração estratégica é também um catalisador para a convergência de energias na organização. À medida que o sistema de remuneração é alinhado ao contexto e à estratégia da organização, constitui um componente de motivação e harmonização de interesses, contribuindo para a construção de valores partilhados e ajudando a gerar visões comuns.

\subsection{Pesquisas Anteriores}

Durante a realização do presente estudo foi realizada uma pesquisa nos anais do EnANPAD - Encontro da ANPAD e na Base de Dados Web of Science - ISI, com vistas a verificar os trabalhos existentes sobre o tema. A escolha do EnANPAD se deu pela sua relevância em nível nacional e pelo seu alinhamento com o tema da pesquisa. Esta pesquisa abrangeu os anos de 2001 a 2011, para levantamento dos artigos foram utilizados como palavras-chave os seguintes termos: Sistemas de Remuneração; Remuneração Variável; e, Remuneração Estratégica. Na Base de Dados Web of Science - ISI as palavras-chave utilizadas para a busca dos artigos foram: compensation systems; variable remuneration; e, remuneration strategy.

No contexto nacional, Martins e Barbosa (2001), discute a participação nos lucros e/ou nos resultados (PLR) como uma forma de remuneração variável. O objetivo era analisar os programas de PLR definidos pelos acordos e convenções coletivas arquivados nas entidades sindicais dos trabalhadores metalúrgicos da região metropolitana de Belo Horizonte. Ducati e Vilela (2001) discutem a questão da participação dos empregados nos lucros ou resultados da empresa, abordando questões referentes à regulamentação deste tipo de remuneração e sua influência na motivação dos trabalhadores. Já Oliveira (2002) apresenta um artigo no qual busca analisar as tendências em remuneração variável adotadas por empresas brasileiras. Para tanto, foi encaminhado questionário exploratório para empresas relacionadas na "Maiores e Melhores" da revista Exame. Os resultados apontaram tendências no que tange à: (i) determinação das bases salariais sobre as quais a 
remuneração variável se dá; (ii) como é traçada a estratégia de remuneração; e, (iii) onde são alicerçadas as práticas de remuneração. Como resultados a autora percebe que existe uma tendência de crescimento na aplicação de remuneração variável nas empresas brasileiras, sendo este tipo de remuneração utilizado por $81,1 \%$ das empresas.

Em 2006, Reis-Neto (2006) desenvolveu artigo no qual pretendia entender a influência da remuneração variável na motivação e no desempenho dos funcionários. Seu artigo teve como objetivo analisar como o programa de remuneração variável adotado por uma empresa pode afetar a motivação e o desempenho. Por fim, Vasconcelos e Silva (2007) apresentaram artigo no qual foi realizada uma pesquisa com 17 empresas brasileiras com o objetivo de identificar critérios, metodologias e ferramentas utilizadas por essas empresas em seus programas de remuneração variável. Neste trabalho os resultados apontaram para a evidência de que (i) o Balanced Scorecard, apesar de bastante mencionado como ferramenta utilizada no planejamento e gestão empresarial, ainda não foi incorporado com a mesma intensidade nos programas de remuneração variável; e, (ii) a dimensão financeira vem perdendo espaço para indicadores que privilegiam ativos intagíveis.

A pesquisa realizada por Coelho e Roglio (2010) buscou identificar as características de um sistema de remuneração para o corpo docente de instituições de ensino superior tendo por base o sistema de remuneração adotado por organizações de outros setores, como conclusão constatou-se que: (i) a remuneração por competências se apresenta como uma tendência para as instituições de ensino tendo em vista, que os docentes são profissionais altamente qualificados e a remuneração funcional não estimula esses profissionais de modo efetivo; (ii) a complementação da remuneração fixa sugere o uso de alguns benefícios, por exemplo, a previdência privada que se mostrou amplamente utilizada; (iii) a adoção da remuneração variável, apesar de não ser muito utilizada pelas instituições de ensino apresenta-se como um perspectiva promissora para a melhoria do desempenho organizacional.

No contexto internacional, Lin, Chang e Lai (2002) realizaram uma pesquisa com o objetivo de investigar o que motiva uma empresa a implantar em seu sistema de remuneração a participação nos lucros. Como resultados constatou-se que as propriedades da função e o esforço do trabalhador são primordiais para que as empresas escolham entre os diferentes sistemas de compensação. Já Chenevert e Tremblay (2002) investigaram se as empresas adotam estratégias internas ou externas ao efetuarem a escolha da política de remuneração, para tanto, foram investigas 252 empresas de Quebec. Os resultados sugerem que as estratégias internas ditam a escolha de política de remuneração, no entanto, as empresas buscam criar consistência interna entre as Políticas de RH e suas estratégias de desenvolvimento organizacional.

Em 2011, Yanadori e Kang investigaram a diferenciação dos sistemas de remuneração interna nas empresas de tecnologia americanas. Como resultados constatou-se que o processo de 
tomada de decisão sobre a remuneração a ser paga é diferente para os funcionários que trabalham com pesquisa e desenvolvimento e os funcionários administrativos. No entanto, observa-se que as empresas procuram encontrar um equilíbrio no processo de personalização dos sistemas de remuneração de acordo com os grupos de funcionário, possibilitando assim a manutenção desse sistema de pagamento e a consistência do mesmo.

A presente pesquisa se difere das pesquisa acima mencionadas, por realizar uma análise sobre o Sistema de Remuneração Variável das organizações Primium Partner Xerox, bem como sua influência no alcance das estratégias propostas.

\section{Metodologia Da Pesquisa}

Esta seção tem por objetivo apresentar a metodologia que informa a presente pesquisa, sendo constituída dos seguintes itens: (i) enquadramento metodológico; (ii) população, amostra e horizonte temporal; (iii) tipos, coleta e análise de dados; e (iv) aplicação da pesquisa.

No que tange ao item (i) enquadramento metodológico - considerando-se o objetivo do presente trabalho, este se caracteriza como sendo exploratório e descritivo. É exploratório, pois visa tornar familiar tanto o assunto quanto a empresa a ser investigada (RUDIO, 1999; CERVO e BERVIAN, 1996; TRIPODI et. al., 1981). Ainda com relação à pesquisas exploratórias, Gil (1999, p. 43) argumenta que este tipo de pesquisa "habitualmente envolve levantamento bibliográfico e documental, entrevistas não padronizadas e estudos de casos”. O mesmo autor (Ibid.) argumenta ainda que estudos exploratórios podem auxiliar o pesquisador a descobrir a "[...] existência de associações entre variáveis", o que está alinhado ao foco do presente estudo, uma vez que busca-se identificar a relação entre o Sistema de Remuneração Variável (SRV) adotado pela empresas participantes do estudo e o atingimento das estratégias organizacionais. É descritivo, pois objetiva descrever as características das estruturas Primium Partner Xerox e analisar as práticas de gestão das referidas empresas em relação ao tema abordado. Conforme Gil (1999, p. 44) este tipo de pesquisa “[...] tem por objetivo primordial a descrição das características de determinada população ou fenômeno ou o estabelecimento de relações entre variáveis". Como método de pesquisa foi utilizado o método de estudo multicasos, o que, conforme Strobel (2005, p. 75) "[...] tem a vantagem de destacar similaridades e divergências entre realidades diferentes, tornando-o mais recomendável para uma análise mais profunda e crítica [...] em organizações similares, mas não homogêneas".

No que tange ao item (ii) população, amostra e horizonte temporal - a população inicial é constituída por todas as organizações Primium Partner Xerox do Brasil, em um total de 24 (vinte e quatro) empresas. Desta população inicial, a amostra utilizada no presente artigo são as empresas 
que retornaram o questionário exploratório encaminhado, perfazendo um total de 12 (doze) empresas, o que pode ser considerado como uma amostra adequada (50\% da população inicial). O horizonte temporal coberto pela pesquisa se constitui no período de um ano, tempo necessário para elaboração do questionário, encaminhamento e recebimento dos mesmos para análise.

No que tange ao item (iii) tipos, coleta e análise de dados - o tipo de dados utilizados na pesquisa se constitui em dados primários, uma vez que são levantados diretamente junto aos gestores das empresas respondentes. Para levantar os dados necessários para o presente estudo, optou-se por utilizar como método de coleta de dados um questionário com questões fechadas e abertas. Segundo Marconi e Lakatos (1999) um questionário é composto por uma série de perguntas que deverão ser respondidas por escrito e, geralmente, sem a presença do entrevistador, tendo como vantagens a minimização do tempo gasto para coletar os dados e a redução da inibição dos respondentes. Para análise dos dados, optou-se por utilizar como ferramenta de intervenção a análise de cluster, técnica que visa agrupar os dados obtidos na pesquisa em grupos nos quais seus integrantes possuem uma maior similaridade entre si que em outros. Por meio desta técnica é possível agrupar os dados de forma tal a gerar maior homogeneidade intra-grupal e maior heterogeneidade inter-grupal (HAIR et. al, 1998).

Finalmente, no que tange ao item (iv) aplicação da pesquisa - em primeiro lugar foi necessária a elaboração de um instrumento de coleta de dados. $\mathrm{O}$ instrumento escolhido para levantamento de dados foi um questionário contendo questões fechadas e abertas, que buscavam levantar questões importantes a respeito da utilização do SRV nas empresas pesquisadas. A escolha por este instrumento se dá pelo fato de que este é geralmente respondido por escrito, sem a presença do entrevistador, sendo encaminhado por correio ou e-mail (MARCONI e LAKATOS, 2007). Como as empresas respondentes se encontram em diversas regiões do país, este instrumento se torna adequado. Uma vez elaborado o questionário, foi necessária uma aplicação-piloto para verificar na prática se as questões elaboradas conseguiam obter os dados necessários para pesquisa. Uma aplicação-piloto busca verificar se o questionário apresenta os seguintes elementos: (i) fidedignidade - qualquer pessoa que aplique o questionário obterá os mesmos resultados; (ii) validade - os dados recolhidos são necessários à pesquisa; e, (iii) operatividade - vocabulário acessível e significado claro (Ibid., 2007). Nesta etapa optou-se por aplicar o questionário em uma das empresas Primium Partner, a saber, Xbramar Soluções e Tecnologia Ltda. Esta empresa foi escolhida pela facilidade de acesso ao diretor da mesma, o que fez com que a aplicação do questionário não sofresse qualquer tipo de restrição. Após a aplicação-piloto o questionário foi revisado, e, considerando o feedback dessa primeira aplicação, foi ajustado e posteriormente aprovado para aplicação na pesquisa propriamente dita. 
$\mathrm{Na}$ aplicação do questionário optou-se pelo encaminhamento do mesmo via e-mail aos diretores das 24 organizações Primium Partner Xerox existentes no Brasil. O questionário foi respondido e devidamente retornado por 12 dessas empresas, sendo esta a amostra utilizada nas análises. Conforme Marconi e Lakatos, (2007), habitualmente têm-se um retorno de 25\% dos questionários encaminhados aos respondentes, sendo assim, a resposta ao questionário encaminhado (50\% da população) pode ser considerada representativa.

\section{Apresentação e Análise dos Resultados}

Esta seção objetiva apresentar as empresas utilizadas na presente pesquisa, coletar dados referentes aos Sistemas de Remuneração Variável (SRV) das mesmas e analisar estes dados, traçando um perfil da utilização do SRV como diferencial competitivo nas empresas analisadas. Para tanto, se divide em 03 (três) sub-seções, a saber: (i) as organizações Primium Partner Xerox apresenta as empresas foco do estudo e traça um perfil das mesmas; (ii) análise dos resultados da pesquisa - envolvendo a estrutura do SRV, o impacto do SRV nas Estratégias Organizacionais e os aspectos que Influenciam a Implantação do SRV; e, por fim, (iv) realiza um cotejamento dos resultados da pesquisa frente aos fundamentos teóricos que orientaram o trabalho.

\subsection{As Organizações Primium Partner}

As empresas Primium Partner Xerox surgiram a partir da estratégia proposta pela Multinacional Xerox de liderar o mercado brasileiro de documentos. Esta estratégia implica no desenvolvimento de serviços e tecnologia, envolvendo consultoria empresarial, contratos de terceirização e soluções integradas. Neste contexto, as empresas Primium Partner Xerox aparecem como parceiras estratégicas criadas com o objetivo de oferecer soluções cada vez mais completas, diferenciadas aos seus clientes e ofertadas diretamente por empresas locais. Estas empresas estão presentes em todo o país e possuem estrutura de vendas, administrativa, técnica e de atendimento a clientes, sendo responsáveis pela administração integrada de todos os aspectos da relação com os clientes em seu território de abrangência. As empresas que responderam ao questionário exploratório são apresentadas na Tabela 1. Nesta tabela é apresentado o código e o nome de cada organização, o número de funcionários, o número de cargos e a região de abrangência.

Como pode ser observado na Tabela 1, o número de funcionários varia de empresa para empresa e a média de funcionários é de 52 por empresa. A variação do número de funcionários se dá pela flexibilidade destas empresas, o território de abrangência de cada empresa e o fato de sua estrutura ser organizada de acordo com o nível de exigência e demandas do mercado na qual estão inseridas. Da mesma forma, o quantitativo de cargos por empresa também varia, sendo em média 08 
(oito) cargos por empresa. As empresas que aparecem com maior número de funcionários são a “Office Total Solução em Tecnologia Ltda.” (150 funcionários) e a “ADM7 Copiadoras Ltda.” (130 funcionários). Importante ressaltar que ambas as empresas tem atuação ampla, no primeiro caso abrangendo todo o estado do Rio de Janeiro e no segundo caso abrangendo os estados de MS, MT, AC, RO, GO, DF e MA. Por outro lado, as empresas que apresentam o menor número de funcionários - "Solumax Soluções e Tecnologia Ltda." (17 funcionários) e "Xbrasul Com. e Rep. Ltda." (14 funcionários), atendem a uma região específica (Grande Curitiba) e parte do estado do Rio Grande do Sul (região entorno da cidade de Caxias do Sul), o que justifica o número de funcionários.

Tabela 1 - Amostra das Empresas

\begin{tabular}{l|l|c|c|l}
\hline \multicolumn{1}{|c|}{ EMPRESA } & No FUNCIONÁRIOS & CARGOS & \multicolumn{1}{|c}{ REGIÃO } \\
\hline NNo & \multicolumn{1}{|c|}{ NOME } & 150 & 13 & Rio de Janeiro (Estado) \\
\hline $\mathbf{0 1}$ & Oficce Total Solução em Tecnologia Ltda. & 038 & 10 & Santa Catarina \\
$\mathbf{0 2}$ & Xbramar Soluções e Tecnologia Ltda. & 043 & 03 & Mato Grosso \\
$\mathbf{0 3}$ & Dimensão Informática Ltda. & 028 & 04 & Rio Grande do Sul \\
$\mathbf{0 4}$ & DCMAX Ltda. & 020 & 07 & Grande Porto Alegre \\
$\mathbf{0 5}$ & Docstore Soluções em Tecnologia Ltda. & 040 & 05 & Rio de Janeiro (Cidade) \\
$\mathbf{0 6}$ & 2 M1 Comercial Ltda. / Xsol Office Solution & 049 & 20 & Espírito Santo \\
$\mathbf{0 7}$ & Doc Soluções comerciais Ltda. & 130 & 10 & MS, MT, AC, RO, GO, DF, MA \\
$\mathbf{0 8}$ & ADM7 Copiadoras Ltda. & 055 & 10 & Grande São Paulo \\
$\mathbf{0 9}$ & Xdivision A Soluções em Documentos Ltda. & 035 & 05 & Santa Catarina \\
$\mathbf{1 0}$ & AX Comércio e Representações Ltda. & 017 & 05 & Grande Curitiba \\
$\mathbf{1 1}$ & Solumax Soluções e Tecnologia Ltda. & 014 & 06 & Rio Grande do Sul \\
$\mathbf{1 2}$ & Xbrasul com. E Rep. Ltda. & $\mathbf{0 5 2}$ & $\mathbf{0 8}$ & \\
\hline Média & &
\end{tabular}

Fonte: Elaboração própria

\subsection{Análise dos Resultados da Pesquisa}

Esta seção adota como critérios de análise a estrutura do SRV, o impacto do SRV nas Estratégias Organizacionais e os aspectos relacionados à implantação do SRV nas empresas analisadas. Passa-se a seguir a discutir individualmente cada um dos critérios.

\section{a. Estrutura do Sistema de Remuneração Variável}

No que tange à estrutura do SRV, a análise está ligada ao entendimento dos seguintes critérios: (i) abrangência do SRV - funcionários que recebem remuneração variável; (ii) base do SRV - indicadores aos quais o SRV está vinculado; (iii) base de cálculo do SRV - valor sobre o qual será calculada a remuneração variável; (iv) amplitude do SRV - limites estabelecidos em relação ao salário definido; e, (v) tipo de remuneração - como é realizada a remuneração variável. Passa-se a seguir a discutir individualmente cada um dos tópicos. Os tópicos são apresentados em forma tabular, sendo que em cada tabela, a coluna 1 apresenta os critérios de análise, as colunas numeradas de 1 a 12 apresentam as respostas dadas por cada organização, a coluna "total" apresenta 
a incidência de respostas em relação a cada critério de análise e, finalmente, a coluna "\%" mostra o percentual de empresas que apresentam cada critério analisado.

Em relação à abrangência do SRV, apresenta-se a Tabela 2. Pode-se perceber que todas as empresas respondentes (100\%) disseram ter o SRV vinculado aos funcionários da área comercial o que, no entendimento dos autores, se configura como uma situação normal, uma vez que estes profissionais são, no mercado, geralmente remunerados por produtividade e se relacionam diretamente com os clientes. Em seguida aparecem os funcionários que detém cargos de gerência e supervisão (83\%), dada sua responsabilidade em fazer com que as equipes superem as metas préestabelecidas e atendam as expectativas dos clientes e demais stakeholders. Por outro lado, percebese que os funcionários não diretamente ligados à área comercial da empresa, em geral não tem parte variável vinculada ao seu salário, haja vista que somente $33 \%$ das empresas respondentes disseram cobrir estes funcionários com o SRV.

Tabela 2 - Abrangência do Sistema de Remuneração Variável

\begin{tabular}{|c|c|c|c|c|c|c|c|c|c|c|c|c|c|c|}
\hline \multirow{2}{*}{\multicolumn{15}{|c|}{$\begin{array}{r}\text { EMPRESAS } \\
\text { ABRANGÉNCIA DO SRV }\end{array}$}} \\
\hline & & & & & & & & & & & & & & \\
\hline Funcionários & & $\mathrm{X}$ & & & & & $\mathrm{X}$ & $\mathrm{X}$ & $\mathrm{X}$ & & & & 04 & $33 \%$ \\
\hline Funcionários da Área Comercial & $\mathrm{x}$ & $\mathrm{x}$ & $\mathrm{X}$ & $\mathrm{x}$ & $\mathrm{x}$ & $\mathrm{X}$ & $\mathrm{X}$ & $\mathrm{X}$ & $\mathrm{X}$ & $\mathrm{X}$ & $\mathrm{X}$ & $\mathrm{X}$ & 12 & $100 \%$ \\
\hline Cargos de Gerência/Supervisão & & $\mathrm{X}$ & $\mathrm{X}$ & $\mathrm{x}$ & $\mathrm{X}$ & $\mathrm{x}$ & $\mathrm{X}$ & $\mathrm{X}$ & $\mathrm{X}$ & & $\mathrm{X}$ & $\mathrm{X}$ & 10 & $83 \%$ \\
\hline Estagiários & & $\mathrm{X}$ & & $\mathrm{x}$ & $\mathrm{x}$ & & & $\mathrm{x}$ & & $\mathrm{X}$ & & $\mathrm{x}$ & 06 & $50 \%$ \\
\hline Terceirizados & & $\mathrm{X}$ & & $\mathrm{x}$ & $\mathrm{X}$ & & & $\mathrm{X}$ & $\mathrm{x}$ & $\mathrm{X}$ & & $\mathrm{x}$ & 07 & $58 \%$ \\
\hline
\end{tabular}

Fonte: Elaboração própria

O segundo critério de análise - Base do SRV - diz respeito ao tipo de indicador de desempenho que é utilizada para alimentar o SRV, ou seja, os critérios levados em consideração para avaliar desempenho aos quais o SRV está atrelado. Como pode ser visualizado na Tabela 3, os critérios de avaliação que emergiram da pesquisa são: (i) alcance de metas; (ii) faturamento; (iii) redução de desperdícios; (iv) produtividade; (v) qualidade do atendimento; e, (vi) outros.

Tabela 3 - Base do Sistema de Remuneração Variável

\begin{tabular}{|c|c|c|c|c|c|c|c|c|c|c|c|c|c|}
\hline EMPRESAS & 1 & 2 & 3 & 4 & 5 & 6 & 7 & 8 & 9 & 1011 & 12 & \multirow[t]{2}{*}{ TOTAL } & \multirow[t]{2}{*}{$\%$} \\
\hline \multicolumn{12}{|l|}{ BASE DO SRV } & & \\
\hline Alcance de Metas & & $X$ & $X$ & $X$ & $X$ & $X$ & $X$ & $X$ & $X$ & $X$ & $X$ & 11 & $92 \%$ \\
\hline Faturamento & & $X$ & $X$ & $X$ & $X$ & & $X$ & $X$ & $X$ & $X$ & $X$ & 09 & $75 \%$ \\
\hline Redução de Desperdícios & & & & & & & & & & & & 00 & $0 \%$ \\
\hline Produtividade & & $X$ & & & & $X$ & & $X$ & $X$ & $X$ & & 05 & $42 \%$ \\
\hline Qualidade do Atendimento & $X$ & $X$ & & & $X$ & & & $X$ & & & & 04 & $33 \%$ \\
\hline Outros & & & & & & & & & & & & 00 & $0 \%$ \\
\hline
\end{tabular}

Fonte: Elaboração própria

O alcance de metas foi considerado o principal motivo utilizado como base para o SRV, com uma participação de $92 \%$ das empresas. Em seguida aparece o faturamento com $75 \%$. A redução de desperdícios não foi utilizada por nenhuma empresa, o que se pode inferir não estar 
relacionado ao foco das empresas em análise, voltado para a área comercial ou esta variável não ser representativa neste tipo de negócio. Outra informação que emerge da Tabela 3 é a composição desta base para o SRV. Pode-se perceber que as empresas, em sua maioria, utilizam mais de um critério de avaliação como base para o SRV. Neste tópico, as empresas 02 (dois) - Xbramar Soluções e Tecnologia Ltda. - e 08 (oito) - ADM7 Copiadoras Ltda. - se destacam, utilizando 04 (quatro) critérios como base para o SRV, a saber: (i) alcance de metas, (ii) faturamento; (iii) produtividade; e, (iv) qualidade do atendimento.

No que tange á base de cálculo para o SRV - valores financeiros que servem de base para o cálculo da remuneração variável - três aspectos emergiram da pesquisa, são eles: (i) salário base do funcionário; (ii) valor fixo; e, (iii) percentual sobre o faturamento. A Tabela 4 apresenta os resultados.

Tabela 4 - Base de Cálculo do Sistema de Remuneração Variável

\begin{tabular}{|c|c|c|c|c|c|c|c|c|c|c|c|c|c|c|}
\hline EMPRESAS & 1 & 2 & 3 & 4 & 5 & 6 & 7 & 8 & 9 & 10 & 11 & 12 & \multirow[t]{2}{*}{ TOTAL } & \multirow[t]{2}{*}{$\%$} \\
\hline \multicolumn{13}{|l|}{ BASE DE CÁLCULO DO SRV } & & \\
\hline Salário Básico do Funcionário & & & & & & & $X$ & & & & & & 01 & $8 \%$ \\
\hline Valor Fixo & & & & & & $X$ & & & & $X$ & & & 02 & $17 \%$ \\
\hline$\%$ Sobre o Faturamento & $X$ & $\mathrm{X}$ & $X$ & $X$ & $X$ & $X$ & $X$ & $\mathrm{X}$ & $X$ & $X$ & $X$ & $X$ & 12 & $100 \%$ \\
\hline
\end{tabular}

Fonte: Elaboração própria

O principal aspecto considerado como base de cálculo do SRV é percentual sobre o faturamento, sendo adotado por $100 \%$ das empresas respondentes. Analisando-se conjuntamente a Tabela 3 e a Tabela 4, percebe-se um alinhamento entre as informações. O faturamento aparece em segundo lugar como informação utilizada como base para o SRV e, paralelamente, aparece como principal valor utilizado como base para o cálculo do SRV. Por fim, é importante ressaltar que as empresas que utilizam outro tipo de informação como base de cálculo, o fazem conjuntamente com o percentual sobre o faturamento, demonstrando a importância deste indicador para o SRV. Apenas uma empresa (6 - 2 M1 Comercial Ltda. / Xsol Office Solution) utiliza o salário base como base de cálculo do SRV. Assim, fica evidenciado que a empresa precisa ter ganhos financeiros para efetuar a distribuição da remuneração variável, sendo o faturamento uma variável objetiva e de total entendimento por parte dos funcionários.

O quarto critério de análise - a amplitude do SRV - diz respeito ao estabelecimento de limites aos valores que a remuneração variável pode atingir em relação ao salário ou aspecto considerado como base de cálculo para o SRV definido pela empresa. Os limites são, especificamente, os percentuais mínimos e máximos estabelecidos para variação deste tipo de remuneração. Importante ressaltar que nos casos em que os limites são informações qualitativas, estas são devidamente identificadas pelo símbolo $(*)$ e detalhadas em notas explicativas, a seguir apresentadas. 
(*) Consultores Vivo tem ajuda de custo combustível (variável de $\mathrm{R} \$ 200,00$ a $\mathrm{R} \$ 800,00$ ) mais X valor por acessos habilitados; RC Xerox tem ajuda de custo combustível (variável de $\mathrm{R} \$ 400,00$ a $\mathrm{R} \$ 800,00)$ mais $6 \%$ sobre o faturamento vendido para o mesmo; Gerente Vivo tem ajuda de custo combustível (variável de $\mathrm{R} \$ 800,00$ a $\mathrm{R} \$ 1000,00$ ) mais $15 \%$ sobre o ganho dos consultores e Supervisores; Gerente de Vendas Xerox tem ajuda de custo combustível (variável de R\$1000,00 a R \$ 1500,00) mais 1\% sobre faturamento dos RCs.

(**) Percentual sobre vendas

Tabela 5 - Amplitude do Sistema de Remuneração Variável

\begin{tabular}{|c|c|c|c|c|c|c|c|c|c|c|c|c|}
\hline \multirow{2}{*}{\multicolumn{11}{|c|}{$\frac{\text { EIMPRESAS }}{\text { AMPLITUDE DO SRV }}$}} & \multirow[t]{2}{*}{ TOTAL } & \multirow[t]{2}{*}{$\%$} \\
\hline & & & & & & & & & & & & \\
\hline \% Mínimo em relação ao Salário Definido & & & & & & $0 \%$ & $10 \%$ & * & & ** & 04 & $33 \%$ \\
\hline \% Máximo em relação ao Salário Definido & & & & & & $35 \%$ & & & & & 01 & $8 \%$ \\
\hline Não tem Limites Definidos & $\mathrm{X}$ & $\mathrm{X}$ & $\mathrm{X}$ & $\mathrm{X}$ & $\mathrm{X}$ & & & & $\mathrm{X}$ & $\mathrm{X}$ & 07 & $58 \%$ \\
\hline
\end{tabular}

Fonte: Elaboração própria

Como pode ser observado na Tabela 5, a maioria das empresas respondentes disse não possuir qualquer tipo de limite em relação à remuneração variável, com uma incidência de $58 \%$ de respostas. Nas análises anteriores percebeu-se uma tendência em utilizar o percentual sobre o faturamento como base de cálculo do SRV, o não estabelecimento de limites aparece como uma estratégia alinhada a esta política, pois pode-se inferir que limitar a remuneração variável gera consequências no faturamento das empresas, uma vez que e equipe pode não ter a mesma motivação para fechar novos negócios após atingir o limite máximo de remuneração estabelecido. Uma argumentação em favor desta hipótese é o fato que apenas uma empresa (6 - 2 M1 Comercial Ltda. / Xsol Office Solution) disse estabelecer limites máximos de remuneração variável (35\% sobre o salário-base). No que se refere aos limites mínimos, estes aparecem de diferentes formas, podendo ser estabelecidos com base em percentual sobre o salário definido, em percentual sobre vendas e, finalmente, pode também aparecer sob a forma de ajuda de custo aos funcionários (neste caso específico, é adotada a prática de subsidiar as despesas com combustível dos funcionários).

Por fim, no que se refere ao tipo de remuneração adotado pelo SRV, a Tabela 6 mostra que são adotados dois tipos de remuneração, a saber: (i) percentual frente às metas estabelecidas; e, (ii) bônus por alcance de metas.

Tabela 6 - Tipo de Remuneração Adotado no Sistema de Remuneração Variável

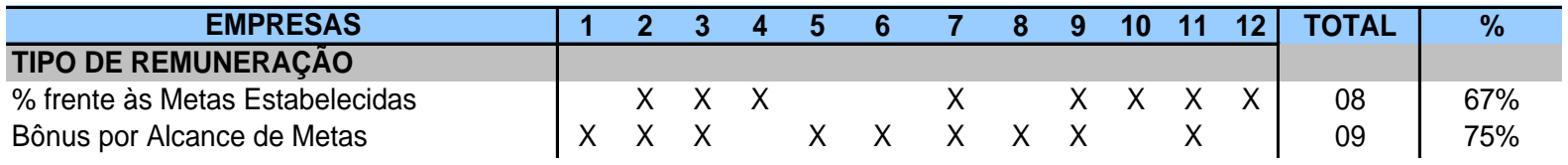

Fonte: Elaboração própria 
De forma geral existe um equilíbrio entre as práticas adotadas sendo que em primeiro lugar aparece a prática de bonificação por alcance de metas com $75 \%$ de incidência. Importante ressaltar que, analisando-se a Tabela 6, percebe-se que determinadas empresas adotam as duas práticas em sua política de remuneração. A seguir passa-se à discussão da próxima sub-seção, que se propõe a analisar o impacto do SRV na implantação das estratégias organizacionais.

b. Impacto do Sistema de Remuneração Variável nas Estratégias Organizacionais

No que tange ao impacto do SRV nas estratégias organizacionais, busca-se analisar o apoio do SRV na implantação e alcance dos objetivos estratégicos das empresas. Para tanto, a análise é calcada nos seguintes aspectos: (i) estratégias alcançadas; (ii) diferenciais competitivos; (iii) contribuições do SRV aos diferenciais competitivos; e, (iv) mudanças percebidas após a implantação do SRV.

Em relação ao primeiro aspecto - estratégias alcançadas - $100 \%$ das empresas entrevistadas disseram que o SRV adotado contribui para o alcance das estratégias. As respostas que emergiram da pesquisa foram agrupadas nos seguintes clusters: (i) estratégias relativas a clientes; (ii) estratégias relativas a pessoas; (iii) estratégias relativas ao crescimento; e, (iv) estratégias relativas ao controle financeiro. De uma forma geral, houve um equilíbrio entre as estratégias apoiadas pelo SRV, com as estratégias relativas a pessoas tendo uma participação maior (67\%). Este fato não é surpresa, dado que o foco principal do SRV são os funcionários da organização. As estratégias relativas ao controle financeiro aparecem em último lugar, respondendo por uma incidência de $17 \%$ das empresas respondentes. Conforme pode ser visualizado na Tabela 7, cada um dos clusters identificados se desdobra em itens explicativos, de acordo com a incidência de respostas.

Tabela 7 - Apoio do SRV ao Alcance das Estratégias Organizacionais 


\begin{tabular}{|c|c|c|c|c|c|c|c|c|c|c|c|c|c|c|}
\hline EMPRESAS & 1 & 2 & 3 & 4 & 5 & 6 & 7 & 8 & 9 & 10 & 11 & 12 & TOTAL & $\%$ \\
\hline \multicolumn{15}{|l|}{ APOIO AO ALCANCE DAS ESTRATÉGIAS } \\
\hline $\begin{array}{l}\text { Sim } \\
\text { Não }\end{array}$ & $\mathbf{x}$ & $\mathbf{X}$ & $\mathbf{X}$ & $\mathbf{X}$ & $\mathbf{X}$ & $\mathbf{X}$ & $\mathbf{x}$ & $\mathbf{X}$ & $\mathbf{X}$ & $\mathbf{X}$ & $\mathbf{X}$ & $\mathbf{x}$ & $\begin{array}{l}12 \\
00\end{array}$ & $\begin{array}{c}100 \% \\
0 \%\end{array}$ \\
\hline \multicolumn{15}{|l|}{ ESTRATÉGIAS ALCANÇADAS } \\
\hline Estratégias Relativas à Clientes & $\mathbf{X}$ & & & $\mathbf{X}$ & & $\mathbf{X}$ & $\mathbf{x}$ & & $\mathbf{X}$ & $\mathbf{X}$ & & & 06 & $50 \%$ \\
\hline Melhoria do relacionamento com clientes & $\mathrm{x}$ & & & & & & $\mathrm{x}$ & & $\mathrm{x}$ & $\mathrm{x}$ & & & 04 & $33 \%$ \\
\hline Captação de clientes & $\mathrm{x}$ & & & $\mathrm{X}$ & & & & & & & & & 02 & $17 \%$ \\
\hline Fidelização de clientes & & & & & & $\mathrm{X}$ & & & & & & & 01 & $8 \%$ \\
\hline Estratégias Relativas à Pessoas & $\mathbf{x}$ & $\mathbf{x}$ & $\mathbf{X}$ & & $\mathbf{x}$ & $\mathbf{X}$ & & $\mathbf{X}$ & & $\mathbf{X}$ & & $\mathbf{X}$ & 08 & $67 \%$ \\
\hline Retenção de talentos humanos & $\mathrm{x}$ & $x$ & $x$ & & & $\mathrm{x}$ & & & & & & & 04 & $33 \%$ \\
\hline Atração de talentos humanos & & $\mathrm{x}$ & $\mathrm{x}$ & & & & & & & & & & 02 & $17 \%$ \\
\hline Manutenção dos talentos humanos & & & & & & & & $\mathrm{X}$ & & & & & 01 & $8 \%$ \\
\hline Mantenção da motivação da equipe & & & & & $\mathrm{X}$ & & & & & $\mathrm{X}$ & & $\mathrm{X}$ & 03 & $25 \%$ \\
\hline Estratégias Relativas ao Crescimento & $\mathbf{x}$ & & $\mathbf{X}$ & & & $\mathbf{X}$ & & $\mathbf{x}$ & $\mathbf{x}$ & $\mathbf{x}$ & $\mathbf{x}$ & & 07 & $58 \%$ \\
\hline Alcance de metas & & & $\mathrm{X}$ & & & & & $\mathrm{X}$ & & & & & 02 & $17 \%$ \\
\hline Aumento da participação de mercado & & & & & & $\mathrm{X}$ & & & $\mathrm{X}$ & $\mathrm{X}$ & $\mathrm{X}$ & & 04 & $33 \%$ \\
\hline Aumento da produtividade & & & & & & & & $\mathrm{X}$ & $\mathrm{X}$ & & & & 02 & $17 \%$ \\
\hline Aumento da rentabilidade & & & & & & & & & & $x$ & & & 01 & $8 \%$ \\
\hline Aumento do faturamento & $\mathrm{x}$ & & & & & & & & & & & & 01 & $8 \%$ \\
\hline Estratégias Relativas ao Controle Financeiro & & & & $\mathbf{x}$ & & & & & $\mathbf{x}$ & & & & 02 & $17 \%$ \\
\hline Redução de inadimplência & & & & & & & & & $x$ & & & & 01 & $8 \%$ \\
\hline Prazos de Pagamento & & & & $\mathrm{x}$ & & & & & & & & & 01 & $8 \%$ \\
\hline
\end{tabular}

Fonte: Elaboração própria

Analisando-se mais detalhadamente cada um dos clusters identificados na Tabela 7, novas informações emergem da pesquisa.

Em relação às estratégias relativas a clientes, a maior preocupação se refere à melhoria do relacionamento com clientes, aparecendo em 33\% das empresas respondentes. Em seguida vem a captação e fidelização de clientes. As respostas dadas pelas empresas apontam para o entendimento de que um melhor relacionamento com clientes leva, consequentemente, a uma melhoria na captação e retenção dos mesmos, sendo assim, justifica-se a maior preocupação com este aspecto.

Em relação às estratégias relativas a pessoas, a preocupação com manter na organização os seus talentos aparece em primeiro lugar, com uma incidência de 33\% das respostas. Em organizações baseadas no conhecimento e, mais especificamente, em organizações com enfoque na área comercial, como as empresas em estudo, a preocupação com a retenção de seus talentos está ligada à manutenção da competitividade da empresa como um todo, justificando a preocupação das respondentes com este critério. Em seguida aparece a manutenção da motivação da equipe, como aspecto alavancado pelo SRV.

Apesar da preocupação com a retenção dos talentos humanos, os dados da pesquisa apontam para uma menor capacidade do SRV em apoiar a atração - trazer pessoas competentes para a empresa - e manutenção - manter capacitados os talentos retidos na empresa - destes talentos, uma vez que apenas 02 (duas) empresas responderam que o SRV apóia a atração de talentos e 01 (uma) respondeu que o SRV apóia sua manutenção.

No que tange às estratégias relativas ao crescimento, $33 \%$ das empresas respondentes acreditam que o SRV influencia positivamente a participação de mercado da empresa, sendo esta a resposta de maior incidência. $\mathrm{O}$ alcance de metas e aumento da produtividade aparecem empatados 
em segundo lugar, com 17\% de incidência cada. Por fim, aumento da rentabilidade e aumento do faturamento foi citado por apenas uma empresa cada.

Finalmente, as estratégias relativas ao controle financeiro parecem não sofrer influência do SRV, conforme as respondentes. Neste item, 01 (uma) empresa citou a redução na inadimplência e 01 (uma) empresa citou a redução nos prazos de pagamento.

O segundo aspecto - diferenciais competitivos - questiona as empresas respondentes em relação aos diferenciais competitivos pelos quais elas são reconhecidas no mercado. As respostas foram agrupadas nos seguintes clusters: (i) atendimento às necessidades do cliente; (ii) equipe de profissionais; e, (iii) imagem da organização.

Conforme pode ser observado na Tabela 8 , o atendimento às necessidades do cliente surge como principal diferencial competitivo das empresas respondentes, com uma incidência de $75 \%$. Em seguida aparece a equipe de profissionais com $58 \%$ e, finalmente, a imagem da organização, com 33\%. Cada um dos clusters identificados é discutido em maiores detalhes a seguir.

Tabela 8 - Diferenciais Competitivos apresentados pelas empresas

\begin{tabular}{|c|c|c|c|c|c|c|c|c|c|c|c|c|c|c|}
\hline EMPRESAS & 1 & 2 & 3 & 4 & 5 & 6 & 7 & 8 & 9 & 10 & 11 & 12 & \multirow[t]{2}{*}{ TOTAL } & \multirow[t]{2}{*}{$\%$} \\
\hline \multicolumn{13}{|l|}{ DIFERENCIAIS COMPETITIVOS } & & \\
\hline Atendimento às Necessidades do Cliente & $\mathbf{X}$ & & $\mathbf{X}$ & $\mathbf{X}$ & & $\mathbf{X}$ & $\mathbf{X}$ & $\mathbf{X}$ & $\mathbf{X}$ & $\mathbf{X}$ & $\mathbf{X}$ & & 09 & $75 \%$ \\
\hline Flexibilidade & $x$ & & & $x$ & & & & & & & & & 02 & $17 \%$ \\
\hline Velocidade no atendimento & $x$ & & & $x$ & & $x$ & $x$ & $x$ & $x$ & $x$ & $x$ & & 08 & $67 \%$ \\
\hline Atendimento às necessidades do Cliente & & & $x$ & & & & $x$ & & $x$ & $x$ & & & 04 & $33 \%$ \\
\hline Serviço pós-venda & & & & $x$ & & & & & & & & $x$ & 02 & $17 \%$ \\
\hline Produtos de valor agregado & & & & & & & & & & & & $x$ & 01 & $8 \%$ \\
\hline Equipe de Profissionais & $\mathbf{X}$ & $\mathbf{X}$ & & & & $\mathbf{X}$ & & $\mathbf{X}$ & $\mathbf{X}$ & $\mathbf{X}$ & $\mathbf{X}$ & & 07 & $58 \%$ \\
\hline Qualificação dos profissionais & & & & & & $x$ & & $x$ & & & & & 02 & $17 \%$ \\
\hline Qualidade no atendimento técnico & & $x$ & & & & $x$ & & & & $x$ & $x$ & & 04 & $33 \%$ \\
\hline Comprometimento da Equipe & $x$ & & & & & & & & & $x$ & & & 02 & $17 \%$ \\
\hline Agressividade no nível de remuneração & & $x$ & & & $x$ & & & & $x$ & & & & 03 & $25 \%$ \\
\hline Imagem da organizaçao & $\mathbf{X}$ & & & & $\mathbf{X}$ & & & & & $\mathbf{X}$ & & $\mathbf{X}$ & 04 & $33 \%$ \\
\hline Credibilidade da organização & $x$ & & & & $x$ & & & & & $x$ & & $x$ & 04 & $33 \%$ \\
\hline Reconhecimento de mercado & $x$ & & & & $x$ & & & & & & & & 02 & $17 \%$ \\
\hline
\end{tabular}

Fonte: Elaboração própria

O cluster atendimento às necessidades do cliente se desdobra em outros 05 (cinco) critérios explicativos, a saber: (i) Flexibilidade - diz respeito à capacidade das empresas de adequar suas práticas às exigências cada cliente e cada contexto específico; (ii) Velocidade no atendimento - diz respeito ao tempo gasto para tender o cliente; (iii) atendimento às necessidades do cliente - diz respeito ao desenvolvimento de uma solução alinhada aos objetivos do cliente; (iv) serviço de pósvenda - diz respeito ao relacionamento com os clientes de forma contínua; e, (vi) produtos de valor agregado - diz respeito à capacidade de apresentar uma solução completa ao cliente. A velocidade no atendimento aparece como principal diferencial competitivo, aparecendo em $67 \%$ das empresas respondentes, em seguida surge o atendimento às necessidades do cliente com 33\% de incidência. Percebe-se que, pelas respostas, as empresas respondentes se diferenciam dos concorrentes pela rapidez na prestação de um serviço alinhado aos objetivos do cliente. Por outro lado, os produtos de 
valor agregado aparecem em última posição, com apenas 01 (uma) empresa considerando este um diferencial.

No que se refere ao cluster equipe de profissionais, este é explicado por outros 04 (quatro) critérios: (i) qualificação dos profissionais - diz respeito ao nível de desenvolvimento dos profissionais em relação às competências necessárias ao negócio; (ii) qualidade no atendimento técnico - diz respeito a efetividade do atendimento realizado pelo pessoal da área técnica; (iii) Comprometimento da equipe - diz respeito ao comprometimento dos profissionais com os objetivos estratégicos da organização; e, (iv) agressividade no nível de remuneração - diz respeito à relação salário variável/fixo praticado pela organização. O principal diferencial competitivo das empresas respondentes é a qualidade no atendimento técnico, com um percentual de 33\%. Essa constatação, em parte pode ser explicada pelo suporte dado pela Organização Xerox às Primium Partner, no que tange à treinamentos e capacitação de suas equipes. Em seguida aparece a agressividade no nível de remuneração, com uma participação de $25 \%$. A qualificação dos profissionais e o comprometimento da equipe aparecem em último lugar, ambos com $17 \%$ de empresas considerando estes os seus diferenciais competitivos.

Finalmente, em relação ao último cluster, imagem da organização, este se divide em: (i) credibilidade da organização - diz respeito á credibilidade das Organizações Xerox de forma geral; e, (ii) reconhecimento de mercado - diz respeito ao reconhecimento, por parte do mercado consumidor, às empresas Primium Partner especificamente. A credibilidade da organização apareceu como principal diferencial competitivo (33\%), o que evidencia que as empresas Primium Partner se valem da credibilidade da marca xerox para sustentar suas posições de mercado. O reconhecimento de mercado é citado por $17 \%$ das empresas respondentes, mostrando, também, a importância da imagem das empresas Primium Partner nos mercados onde atuam.

O terceiro aspecto - contribuições do SRV aos diferenciais competitivos - questiona as empresas respondentes em relação aos diferenciais competitivos que tiveram uma melhoria em seu desempenho por meio da utilização do SRV. As respostas foram agrupadas nos mesmos clusters encontrados no aspecto anterior, a saber: (i) atendimento às necessidades do cliente; (ii) equipe de profissionais; e, (iii) imagem da organização. Nesta segunda análise a intenção é evidenciar se o SRV ajuda a desenvolver os diferenciais competitivos entendidos pelas empresas respondentes como os mais importantes, a Tabela 9 apresenta os resultados encontrados.

Tabela 9 - Contribuições do Sistema de Remuneração Variável aos Diferenciais Competitivos 


\begin{tabular}{|c|c|c|c|c|c|c|c|c|c|c|c|c|c|c|}
\hline \multirow{2}{*}{$\begin{array}{l}\text { EMPRESAS } \\
\text { CONTRIBUIÇÕES DO SRV AOS DIFERENCIAIS }\end{array}$} & 1 & 2 & 3 & 4 & 5 & 6 & 7 & 8 & 9 & 10 & 11 & 12 & \multirow[t]{2}{*}{ TOTAL } & \multirow[t]{2}{*}{$\%$} \\
\hline & & & & & & & & & & & & & & \\
\hline Atendimento às Necessidades do Cliente & $\mathbf{X}$ & & & $\mathbf{X}$ & & $\mathbf{X}$ & $\mathbf{X}$ & & & $\mathbf{X}$ & $\mathbf{X}$ & $\mathbf{X}$ & 07 & $58 \%$ \\
\hline Velocidade no atendimento & $\mathrm{x}$ & & & $\begin{array}{l}x \\
x\end{array}$ & & $\mathrm{x}$ & & & & & $\mathrm{x}$ & & 04 & $\begin{array}{r}0 \% \\
33 \%\end{array}$ \\
\hline Atendimento às necessidades do Cliente & & & & & & & $x$ & & & $x$ & & & 02 & $17 \%$ \\
\hline Serviço pós-venda & & & & $\mathrm{x}$ & & & & & & & & $\mathrm{x}$ & 02 & $17 \%$ \\
\hline Produtos de valor agregado & & & & & & & & & & & & $\mathrm{x}$ & 01 & $8 \%$ \\
\hline Equipe de Profissionais & $\mathbf{x}$ & $\mathbf{x}$ & $\mathbf{X}$ & & $\mathbf{X}$ & $\mathbf{X}$ & & $\mathbf{X}$ & $\mathbf{x}$ & $\mathbf{X}$ & $\mathbf{X}$ & & 09 & $75 \%$ \\
\hline Qualificação dos profissionais & & & $\mathrm{x}$ & & & & & $\mathrm{x}$ & & & & & 02 & $17 \%$ \\
\hline Qualidade no atendimento técnico & & $\mathrm{x}$ & & & & $\mathrm{x}$ & & & & $\mathrm{x}$ & $\mathrm{x}$ & & 04 & $33 \%$ \\
\hline Comprometimento da Equipe & $\mathrm{x}$ & $\mathrm{x}$ & & & & & & & & $\mathrm{x}$ & & & 03 & $25 \%$ \\
\hline Agressividade no nível de remuneração & & & & & $\mathrm{x}$ & & & & $\mathrm{x}$ & & & & 02 & $17 \%$ \\
\hline Imagem da organizaçao & & & & & & & & & & & & & 00 & $0 \%$ \\
\hline Credibilidade da organização & & & & & & & & & & & & & 00 & $0 \%$ \\
\hline Reconhecimento de mercado & & & & & & & & & & & & & 00 & $0 \%$ \\
\hline
\end{tabular}

Fonte: Elaboração própria

De uma maneira geral, apesar das empresas respondentes consideraram o atendimento às necessidades dos clientes o seu principal diferencial competitivo, percebe-se que o SRV tem um maior impacto na equipe de profissionais, sendo este o aspecto mais citado ( $75 \%$ das empresas). $\mathrm{O}$ atendimento às necessidades do cliente aparece em segundo lugar, com 58\% de respostas. Os resultados encontrados não surpreendem, pois, apesar do entendimento da importância em atender as necessidades do cliente, o SRV acaba atuando de forma mais pontual na equipe de profissionais, dada a sua natureza. Por fim, apesar de ser considerada como um diferencial competitivo por $33 \%$ das empresas respondentes, a imagem da organização, segundo os dados da pesquisa, não é influenciada pelo SRV.

Analisando-se em detalhes cada um dos clusters, percebe-se: (i) no que tange ao atendimento às necessidades do cliente, a principal contribuição do SRV é na velocidade do atendimento, sendo esta a resposta dada por 33\% das empresas; (ii) no que tange à equipe de profissionais, a principal contribuição do SRV se refere a melhoria da qualidade do atendimento técnico prestado pelas empresas, com 33\%.; finalmente, (iii) no que tange à imagem da organização, esta não foi considerada como um diferencial competitivo alavancado pelo SRV.

O último aspecto referente ao impacto do SRV nas estratégias das organizações aborda as mudanças percebidas após a sua implementação. Como pode ser observado na Tabela 10, todas as empresas respondentes acreditam que surgiram mudanças após a implementação, sendo que as principais foram as seguintes: (i) melhoria no atendimento ao cliente - no que tange à velocidade de atendimento, flexibilidade, serviços de pós-venda, produtos de valor agregado e atendimento às necessidades do cliente em geral; (ii) comprometimento com a empresa - no que tange ao alinhamento dos objetivos pessoais com os objetivos da organização; (iii) valorização pessoal - no que tange à melhoria da auto-estima da equipe; (iv) aumento da motivação - no que tange a capacidade de se auto-motivar da equipe; e, (v) aumento da competitividade - no que tange à competição interna e externa. 
Tabela 10 - Mudanças Percebidas após a Implementação do Sistema de Remuneração Variável

\begin{tabular}{|c|c|c|c|c|c|c|c|c|c|c|c|c|c|c|}
\hline EMPRESAS & 1 & 2 & $\begin{array}{ll}3 & 4 \\
\end{array}$ & 4 & 5 & 6 & 7 & 8 & 9 & 10 & 11 & 12 & \multirow[t]{2}{*}{ TOTAL } & \multirow[t]{2}{*}{$\%$} \\
\hline \multicolumn{13}{|c|}{ MUDANÇAS APÓS IMPLEMENTAÇÃO DO SRV } & & \\
\hline $\begin{array}{l}\text { Sim } \\
\text { Não }\end{array}$ & $\mathbf{X}$ & $\mathbf{X}$ & $\mathbf{X} X$ & $\mathbf{X}$ & $\mathbf{X}$ & $\mathbf{X}$ & $\mathbf{X}$ & $\mathbf{X}$ & $\mathbf{X}$ & $\mathbf{X}$ & $\mathbf{X}$ & $\mathbf{x}$ & $\begin{array}{l}12 \\
00\end{array}$ & $\begin{array}{c}100 \% \\
0 \%\end{array}$ \\
\hline \multicolumn{15}{|l|}{ MUDANÇAS PERCEBIDAS } \\
\hline Melhoria no atendimento aos clientes & $x$ & & & & $\mathrm{x}$ & & $x$ & $\mathrm{x}$ & $x$ & $x$ & & & 06 & $50 \%$ \\
\hline Comprometimento com a empresa & & $x$ & & $x$ & & $x$ & & & $x$ & $x$ & $x$ & $x$ & 07 & $58 \%$ \\
\hline Valorização pessoal & & $\mathrm{x}$ & & & & & & $x$ & & & & & 02 & $17 \%$ \\
\hline Aumento da motivação & & & & $x$ & & & & $x$ & $x$ & $x$ & & & 04 & $33 \%$ \\
\hline Aumento da competitividade & & & & & $\mathrm{x}$ & & $x$ & & & & $x$ & & 03 & $25 \%$ \\
\hline
\end{tabular}

Fonte: Elaboração própria

O comprometimento com a empresa aparece em primeiro lugar entre as mudanças percebidas, com uma incidência de $58 \%$ de respostas. A partir do entendimento deste critério como sendo o alinhamento de objetivos pessoais e organizacionais, percebe-se que uma vez que os ganhos dos funcionários estão atrelados aos ganhos da empresa, estes passam a tomar as decisões buscando o melhor retorno possível para a empresa, o que consequentemente, refletirá em seus ganhos pessoais. Em seguida aparece a melhoria no atendimento aos clientes (50\%), o que pode estar relacionado à melhoria do comprometimento com a empresa, dado que funcionários mais comprometidos acabam prestando um melhor atendimento aos clientes. A seguir passa-se à discussão da última sub-seção referente à apresentação e análise dos dados, que se propõe a analisar os aspectos que influenciam a implantação do SRV nas empresas pesquisadas.

c. Aspectos Relacionados à Implantação do Sistema de Remuneração Variável

No que tange aos aspectos que influenciam a implantação do SRV, busca-se analisar o processo de implantação do SRV nas empresas pesquisadas. Nesta análise, a preocupação se refere aos (i) aspectos facilitadores na implantação do SRV; (ii) aspectos dificultadores na implantação do SRV; e, (iii) influência da CLT e legislação correlata na adoção do SRV. Por fim, as empresas participantes da pesquisa são questionadas quanto a (i) sugestões de melhorias na legislação vigente e (ii) processos trabalhistas gerados pelo SRV. Passa-se a seguir a discutir individualmente cada um dos aspectos.

Em relação ao primeiro aspecto - aspectos facilitadores na implantação do SRV - as respostas que emergiram da pesquisa foram agrupadas em três clusters, a saber: (i) aspectos mercadológicos - diz respeito ao ambiente competitivo na qual as empresas estão inseridas; (ii) aspecto interpessoais - diz respeito à percepção dos funcionários em relação ao SRV em implantação; e, (iii) aspectos operacionais - diz respeito aos processos internos das empresas que facilitaram a implantação do SRV. Conforme pode ser observado na Tabela 11, os aspectos 
operacionais foram os que mais contribuíram na implantação do SRV (83\%), ou seja, pode-se dizer que os processos adotados pelas empresas respondentes estão alinhados á proposta do SRV. Por outro lado, os aspectos mercadológicos não foram considerados influentes na implantação do SRV. A seguir passa-se a discutir cada um dos aspectos individualmente.

Tabela 11 - Aspectos Facilitadores na Implantação do Sistema de Remuneração Variável

\begin{tabular}{|c|c|c|c|c|c|c|c|c|c|c|c|c|c|c|}
\hline EMPRESAS & 1 & 2 & 3 & 4 & 5 & 6 & 7 & 8 & 9 & 10 & 11 & 12 & TOTAL & $\%$ \\
\hline \multicolumn{15}{|l|}{ ASPECTOS QUE FACILITARAM A IMPLANTAÇÃO } \\
\hline Aspectos Mercadológicos & & & & & & & & & $\mathbf{X}$ & & & $\mathbf{X}$ & 02 & $17 \%$ \\
\hline Pesquisa de mercado & & & & & & & & & $x$ & & & & 01 & $8 \%$ \\
\hline Referência da concorrência & & & & & & & & & $x$ & & & $x$ & 02 & $17 \%$ \\
\hline Aspectos Interpessoais & & $\mathbf{x}$ & & & & $\mathbf{x}$ & $\mathbf{x}$ & & & & & $\mathbf{x}$ & 04 & $33 \%$ \\
\hline Receptividade dos funcionários & & $x$ & & & & & $x$ & & & & & & 02 & $17 \%$ \\
\hline Criação de clima motivacional & & $x$ & & & & $x$ & & & & & & $x$ & 03 & $25 \%$ \\
\hline Transparência no processo & & & & & & & $x$ & & & & & & 01 & $8 \%$ \\
\hline Competitividade interna & & $x$ & & & & & & & & & & & 01 & $8 \%$ \\
\hline Aspectos Operacionais & $\mathbf{x}$ & & $\mathbf{x}$ & $\mathbf{x}$ & $\mathbf{x}$ & $\mathbf{X}$ & $\mathbf{X}$ & $\mathbf{x}$ & $\mathbf{x}$ & $\mathbf{X}$ & $\mathbf{x}$ & & 10 & $83 \%$ \\
\hline Experiência anterior & $x$ & & & & & & & $x$ & & & & & 02 & $17 \%$ \\
\hline Possibilidade de ganho atrelado a produção/vendas & $x$ & & $x$ & $\mathrm{x}$ & $\mathrm{x}$ & & $x$ & & & $x$ & $x$ & & 07 & $58 \%$ \\
\hline Atualizações de acordo com o plano de negócios & $x$ & & & & & & & & & & & & 01 & $8 \%$ \\
\hline Simplicidade do sistema de remuneração & & & & & & $x$ & & & & & & & 01 & $8 \%$ \\
\hline Oportunidade de redução de despesas fixas & & & & & & & $x$ & & & & & & 01 & $8 \%$ \\
\hline Resultado & & & & & & & & & $x$ & & & & 01 & $8 \%$ \\
\hline
\end{tabular}

Fonte: Elaboração própria

Em relação aos aspectos mercadológicos, estes foram considerados como fatores que facilitaram a implantação do SRV por apenas duas empresas, sendo assim, não foram considerados importantes na implantação. Os aspectos considerados foram (i) pesquisas de mercado - realizadas pela empresa respondentes com vistas a identificar o SRV utilizado pelas empresas concorrentes e (ii) referência de mercado - com vistas a identificar os sistemas mais utilizados no setor.

No que tange aos aspectos interpessoais, a criação de um clima motivacional foi o principal facilitador na implantação do SRV, com $45 \%$ de incidência. A receptividade dos funcionários aparece em segundo lugar (17\%), seguida da transparência no processo e competitividade interna com $8 \%$ e incidência cada.

Por fim os aspectos operacionais aparecem como principal facilitador na implantação do SRV, com $83 \%$ de incidência. Importante frisar que estes processos dizem respeito a processo internos utilizados pela empresa propriamente ditos e também a experiência acumulada pelos funcionários em experiências anteriores com SRVs. O principal aspecto facilitador foi a possibilidade de ganhos atrelados a produção/vendas (58\%), aspecto este diretamente ligado ao SRV, haja vista que este se baseia na produtividade dos funcionários. Em seguida aparece a experiência anterior dos funcionários com este tipo de sistema, o que facilita a transição do sistema tradicional para o SRV. Os outros aspectos que surgiram foram a possibilidade de atualizações de acordo com o plano de negócios, a simplicidade do sistema de remuneração, a oportunidade de redução de despesas fixas e os próprios resultados da empresa. 
Em relação aos aspectos que dificultaram a implantação do SRV, as respostas foram divididas em (i) aspectos interpessoais e (ii) aspectos operacionais. Um fato interessante foi que 4 (quatro) empresas não disseram ter qualquer tipo de dificuldade com a implantação do SRV, o que corresponde a $33 \%$ das empresas respondentes. A Tabela 12 apresenta os resultados encontrados. Como pode ser observado por esta tabela, os aspectos operacionais mais uma vez aparecem como principal fator de influência na implantação do SRV, com 50\% de incidência. A seguir passa-se a discutir individualmente cada um dos clusters.

Tabela 12 - Aspectos dificultadores na Implantação do Sistema de Remuneração Variável

\begin{tabular}{|c|c|c|c|c|c|c|c|c|c|c|c|c|c|}
\hline \multirow{2}{*}{$\begin{array}{l}\text { EMPRESAS } \\
\text { ASPECTOS QUE DIFICULTARAM A IMPLANTAÇÃO }\end{array}$} & 1 & 2 & 3 & 4 & 5 & 6 & 7 & 8 & 9 & 10 & 12 & \multirow[t]{2}{*}{ TOTAL } & \multirow[t]{2}{*}{$\%$} \\
\hline & & & & & & & & & & & & & \\
\hline Aspectos Interpessoais & & & $\mathbf{X}$ & $\mathbf{X}$ & & & & & & & & 02 & $17 \%$ \\
\hline Restrições quanto a utilização do SRV & & & $\mathrm{x}$ & & & & & & & & & 01 & $8 \%$ \\
\hline Internalização de cultura baseada em desempenho & & & & $\mathrm{x}$ & & & & & & & & 01 & $8 \%$ \\
\hline Aspectos Operacionais & & & & & $\mathbf{X}$ & $\mathbf{x}$ & $\mathbf{x}$ & & $\mathbf{x}$ & $\mathbf{x}$ & $\mathbf{x}$ & 06 & $50 \%$ \\
\hline Desequilíbrio na remuneração & & & & & $x$ & & & & & & & 01 & $8 \%$ \\
\hline Sistemas de cálculo e apuração & & & & & & $x$ & $x$ & & & & & 02 & $17 \%$ \\
\hline Possibilidade de aumento de custos & & & & & & & & & $x$ & & & 01 & $8 \%$ \\
\hline Legislação e encargos trabalhistas & & & & & & & & & & $\mathrm{x}$ & $\mathrm{x}$ & 02 & $17 \%$ \\
\hline Não identificou dificuldades & & $\mathbf{x}$ & & & & & & $\mathbf{X}$ & & & & 04 & $33 \%$ \\
\hline
\end{tabular}

Fonte: Elaboração própria

Ainda no que se refere à Tabela 12, os aspectos interpessoais responderam por $17 \%$ de incidência, sendo que se dividiu em (i) restrições quanto à utilização do SRV - no que diz respeito a aceitação do SRV por parte dos funcionários e (ii) internalização da cultura baseada no desempenho - no que diz respeito a consequências e cobranças em torno das metas a serem alcançadas. No que tange aos aspectos operacionais, este foi considerado o principal dificultador, com uma incidência de 50\% de respostas. Estes aspectos operacionais se subdividem em: (i) desequilíbrio na remuneração - variação nos ganhos mensais e impactos desta na motivação dos funcionários; (ii) sistema de cálculos e apuração - complexidade do SRV; (iii) possibilidade de aumento de custos atrelado a tributação sobre o salário variável; e, (iv) legislação e encargos trabalhistas - atrelado a incidência de tributos sobre o salário dos funcionários. Percebe-se que os principais dificultadores são os sistemas de cálculo e apuração (17\%) e legislação e encargos (17\%). O primeiro se dá pelo fato de a complexidade do SRV muitas vezes dificultar para o funcionário realizar projeções de ganhos e ter a noção do quanto irá receber; o segundo se dá pela carga tributária que incide sobre o salário dos funcionários, principalmente sobre o salário variável, o que dificulta a utilização do SRV de forma mais incisiva.

Finalmente, no aspecto influência da CLT e legislação correlata na adoção do SRV, os resultados da pesquisa são apresentados na Tabela 13. Nesta tabela, além da (i) influência da legislação na adoção do SRV, apresentam-se as (ii) sugestões dadas pelas empresas respondentes 
para melhoria na legislação vigente e questiona-se sobre (iii) processos trabalhistas gerados pelo SRV. A seguir cada um destes aspectos será discutido detalhadamente.

Tabela 13 - Influência da Legislação na Adoção do Sistema de Remuneração Variável

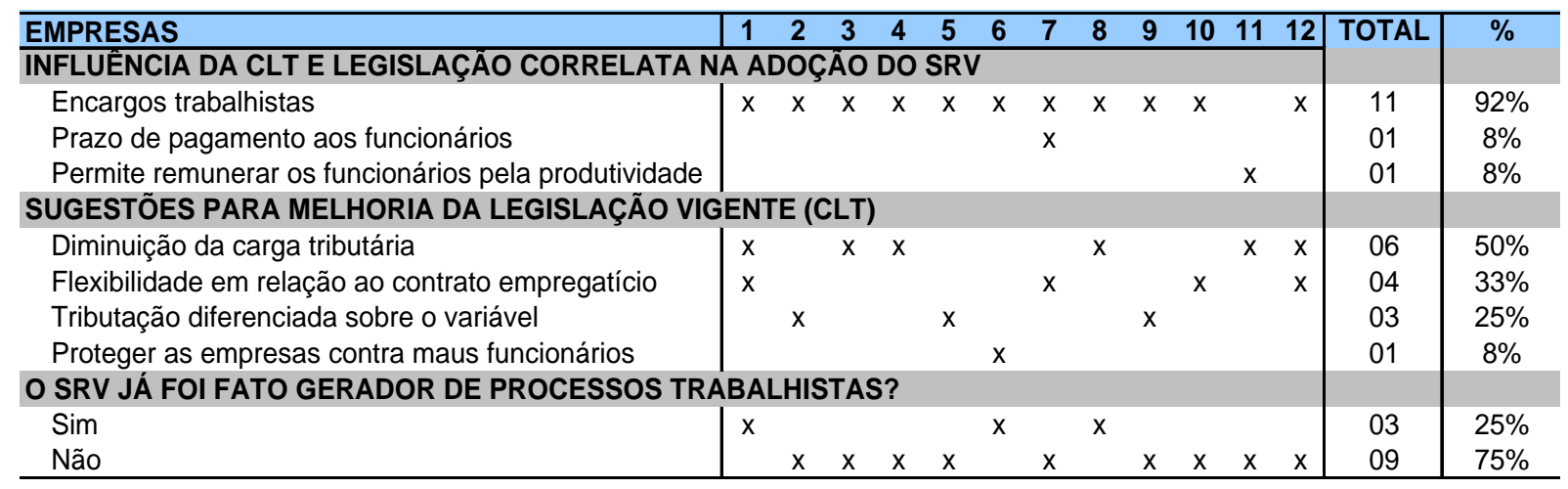

Fonte: Elaboração própria

Como pode ser percebido na Tabela 13, os encargos trabalhistas são o principal fator que influencia a adoção do SRV (92\%), neste caso, conforme as empresas respondentes, de forma negativa, pois o valor dos encargos que incidem sobre a parte variável dos funcionários é considerada alta, dificultando a disseminação desta prática. A possibilidade de remunerar os funcionários pela produtividade e a diminuição no prazo de pagamento dos funcionários foi considerada como influência por 01 (uma) empresa cada.

Em relação às sugestões para melhoria da legislação vigente, as empresas respondentes citaram a diminuição da carga tributária como principal melhoria (50\% de incidência). Segundo as respondentes, a elevada carga tributária não induz a contratação de novos funcionários e diminui a competitividade dos salários que podem ser praticados pelas empresas, dificultando a atração e retenção de talentos humanos. A flexibilidade em relação ao contrato de trabalho aparece com 33\% de incidência, sendo entendida como uma maior autonomia na relação empresa/empregado no estabelecimento das cláusulas contratuais. A tributação diferenciada sobre o variável aparece com $25 \%$ de incidência sendo entendida como a utilização de uma carga tributária inferior sobre os valores recebidos pelos funcionários em regime variável, o que permitiria distribuir uma maior margem dos resultados. Por fim, uma empresa sugeriu o desenvolvimento de ferramentas de controle que permitissem às empresas se protegerem contra maus funcionários.

De qualquer forma, como pode ser evidenciado na Tabela 13, 75\% das empresas respondentes não sofreram qualquer tipo de processo trabalhista devido à utilização do SRV, o que mostra a existência de uma aceitação por parte dos funcionários desta forma de remuneração. 


\section{Resultados da Pesquisa frente aos Fundamentos Teóricos}

Esta seção tem por objetivo cotejar os resultados da pesquisa com o referencial teórico utilizado com vistas a verificar alinhamento de idéias entre o que está posto na literatura e o que surgiu a partir do levantamento aqui realizado.

Em relação à estrutura do SRV, constatou-se que todas as empresas respondentes adotam algum tipo de SRV em seu dia-a-dia, e, particularmente, os funcionários da área comercial possuem remuneração variável em todas as empresas analisadas. Essa constatação vai ao encontro das idéias de Mintzberg (2001) quando esse autor afirma que as organizações envolvem em suas linhas estruturais as equipes e os sistemas de promoção. Importante também ressaltar que este resultado (adoção de SRV por 100\% das respondentes) corrobora a afirmação de Oliveira (2002) quando este autor argumenta que existe um crescimento na utilização de remuneração variável nas empresas brasileiras.

Ainda com relação à estrutura do SRV os resultados da pesquisa apontaram para a utilização do critério alcance de metas como principal base do SRV (92\% das respondentes adotam este critério). Uma vez que para alcançar as metas estabelecidas os funcionários deverão utilizar suas competências e habilidades, pode-se evidenciar que esta postura por parte das empresas analisadas está alinhada com o argumento de Vasconcellos e Silva (2007), quando esses autores afirmam que a dimensão financeira vem perdendo espaço para os intangíveis na concepção do SRV. Por outro lado, quando analisada a base de cálculo do SRV, ficou clara a tendência de se utilizar do faturamento com informação principal (100\% das empresas respondentes adotam este critério) o que contraria a afirmação desses mesmos autores (Ibid.). Apesar da ênfase no faturamento como base de cálculo do SRV, percebeu-se que este critério é utilizado em conjunto com outro tipo de informação, o que nos leva novamente á acreditar na força dos intangíveis como informação para utilização de remuneração variável.

Quanto ao impacto do SRV nas estratégias organizacionais, Porter (1990) afirma que a essência da formulação de uma estratégia competitiva é relacionar a empresa com o meio ambiente onde esta atua. Neste mesmo sentido, Wood e Picarelli (1996) argumentam que a remuneração estratégica deve considerar o que a empresa é hoje e o que ela deseja ser no futuro. No caso das empresas analisadas, uma vez que estas se configuram como prestadoras de serviço, para que consigam um posicionamento competitivo no futuro devem ter suas estratégias alinhadas com suas características internas e com o ambiente onde atuam. Nesse sentido os resultados da pesquisa foram coerentes, haja vista que as empresas respondentes afirmaram que o SRV apóia as estratégias ligadas principalmente às pessoas, uma vez que essas serão as principais responsáveis pela satisfação do cliente final. Além disso, os resultados apontaram o atendimento às necessidades do 
cliente como principal diferencial competitivo das empresas analisadas (75\% das empresas), diferencial este que passa, necessariamente, pelas pessoas na organização.

Por fim, os resultados da pesquisa apontaram que a retenção de talentos humanos e a manutenção da motivação da equipe é alavancada pelo SRV, constatação esta que vai ao encontro dos argumentos de que o SRV ajuda a melhorar a motivação das equipes (DUCATI e VILELA, 2002; REIS NETO, 2006)

\section{Conclusões e Recomendações}

Atualmente a discussão sobre sistemas de remuneração vem tomando cada vez mais espaço tanto no meio empresarial quanto no meio acadêmico. Este fato ocorre devido aos sistemas de remuneração tradicionais já não atenderem às expectativas do mercado e dos profissionais, uma vez que não diferenciam os profissionais pelo seu desempenho. Para lidar com essa situação, surgem os Sistemas de Remuneração Variável, que buscam alinhar os sistemas de remuneração às estratégias organizacionais.

O presente artigo se insere neste contexto, visando analisar o SRV das empresas Primium Partner Xerox, com o objetivo de determinar como o SRV ajuda a alavancar a organização, gerando diferenciais competitivos e alinhando objetivos e estratégias. A proposta foi informada por uma Pergunta de Pesquisa (PP), que, neste momento, é transcrita abaixo e devidamente respondida: PP Quais são as estratégias organizacionais cujo alcance pode ser alavancado por meio da implantação e manutenção de um Sistema de Remuneração Variável (SRV)?

A partir dos resultados da pesquisa aqui realizada, pôde-se evidenciar que, no que tange ao impacto do SRV nas estratégias organizacionais, este se dá principalmente nas estratégias relativas às pessoas, com uma incidência de $67 \%$ de empresas. Este impacto é percebido como responsável por alavancar os diferenciais competitivos, principalmente na retenção de talentos humanos dentro das organizações (33\%) e na manutenção da motivação da equipe (25\%).

No que tange à contribuição do SRV ao desenvolvimento dos diferenciais competitivos das organizações, ficou evidenciado que esta também se dá sobre a equipe de profissionais, com uma incidência de $75 \%$, alavancando a qualidade do atendimento técnico dos funcionários (33\%) e o comprometimento da equipe com os resultados da organização (25\%).

Como aspectos facilitadores à implementação do SRV, os aspectos operacionais apareceram como principal facilitador - $83 \%$ das empresas responderam que estes aspectos facilitam a implementação do SRV - principalmente no que tange à possibilidade de ganhos atrelados a produção/vendas (58\%). Por outro lado, os aspectos operacionais foram também considerados como fatores dificultadores à implementação do SRV por 50\% das empresas. Nesses casos, as 
dificuldades se devem ao sistema de cálculo e apuração (17\%) e a legislação e encargos trabalhistas (17\%). Ainda no que se refere aos encargos trabalhistas, 92\% das empresas entrevistadas consideram que estes influenciam de forma negativa a adoção do SRV, uma vez que os encargos tributários que incidem sobre a parcela variável da remuneração são considerados altos pelas empresas respondentes.

Em relação às limitações da presente pesquisa, considera-se que (i) o tempo para desenvolvimento da pesquisa não foi o suficiente para conseguir acessar todas as empresas Primium Partner Xerox. Apesar da amostra da pesquisa ser representativa, com a inclusão das outras empresas resultados diferentes poderiam emergir; (ii) os critérios de avaliação utilizados nos Sistemas de Remuneração Variável adotados pelas empresas respondentes não foram analisados individualmente de forma mais detalhada; e, (iii) a distância entre as empresas respondentes e o local de moradia dos pesquisadores dificultou uma melhor comunicação entre as partes, que foi realizada exclusivamente por e-mail. Acredita-se que em um contato mais direto com os respondentes, novas questões ou preocupações relativas aos Sistemas de Remuneração Variável poderiam emergir.

As limitações apresentadas podem ser vistas como recomendações para futuros trabalhos, entre eles citam-se: (i) replicar a pesquisa abrangendo todas as empresas Primium Partner existentes no território nacional, desta forma a amostra seria exaustiva e o resultados mais confiáveis; e, (ii) tentar desenvolver a pesquisa por meio de entrevistas semi-estruturadas diretamente com os respondentes, dando a possibilidade de discussão mais direcionada e dinâmica, gerando resultados mais representativos.

\begin{abstract}
:
From the 1990's on, many organizations started the restructuring and transformation of the work cultures, by remodelling their remuneration strategies in search of competitive advantages in the sectors in which they operate. This paper is developed within this context, aiming at addressing the following question: What are the organizational strategies whose range can be levered by means of the implementation and maintenance of a Variable Remuneration System (VRS)? The objective of the study is to analyse how the VRS in the organizations Primium Partner Xerox is capable of promoting the creation of competitive differentials for such organizations in view of the marked in which they participate. The study, of an exploratory and descriptive basis, makes use of a multicase study as the research method. The sampling used is made of the 12 (twelve) firms which answered the questionnaire proposed, the data being considered primary, as they are elicited from the directors of the respondent firms. The results of the study point to the following: (i) the impact of VRS on organizational strategies is felt in relation to those strategies concerned with individuals, mainly with regard to the retention of talents in the organization; (ii) the competitive differentials levered by VRS are linked to the improvement of quality in the technical support rendered by the employees and to the commitment of the team with the results of the organization.
\end{abstract}

Key-Words: Strategy; Strategic Remuneration; Variable Remuneration System. 


\section{Referências}

AlbuQuerque, L. G. de Estratégias de Recursos Humanos e Competitividade. In: VIEIRA, M. M. F.; OLIVEIRA, L. M. B. de (Org.) Administração Contemporânea: Perspectivas e Estratégias. São Paulo: Atlas, 1999.

CERVO, A. L.; BERVIAN, P. A. Metodologia Científica. 4ª Ed. São Paulo: Makron, 1996.

CHENEVERT, D.;TREMBLAY, M. Role of external and internal strategies in the choice of compensation policies. Relations Industrielles-Industrial Relations, v.57, n.2, p.331-353. 2002.

COELHO, E. T. B., ROGLIO, K. D. Remuneração Estratégica: Um estudo qualitativo em Instituições de Ensino e Empresas de outros setores. Encontro da ANPAD - EnANPAD, 2010.

DUCATI, E.; VILELA, E. S. A Participação nos Lucros ou Resultados e a Avaliação de Desempenho. Encontro da ANPAD - EnANPAD, 2001.

FLANERY, T.P., HOFRICHTER, D, PLATTEN, P.E. Participação nos lucros ou resultados: Estratégias e táticas de remuneração dinâmicas. In: Pessoas, desempenho e salários. São Paulo: Futura, 1997.

GIL, A. C. Métodos e Técnicas em Pesquisa Social. $5^{\text {a }}$ Ed. São Paulo: Atlas, 1999.

HAIR JR, J.F.; R.E. ANDERSON; R.L. TATHAM e W.C. BLACK. Multivariate Data Analysis. 5th ed. Upper Saddle River: Prentice Hall, 1998, 730p.

LIN, C. C., CHANG, J. J.;LAI, C. C. Profit sharing as a worker discipline device. Economic Modelling, v.19, n.5, p.815-828. 2002.

cross ref

MARCONI, M. de A.; LAKATOS, E. M. Fundamentos de Metodologia Científica. 6a Ed. São Paulo: Atlas, 2007.

MARTINS, S. S.; BARBOSA, A. C. Q. Participação nos Lucros e/ou Resultados: Uma Forma de Remuneração Variável? Um Estudo no Setor Metalúrgico da Região Metropolitana de Belo Horizonte. Encontro da ANPAD EnANPAD, 2001.

MINTZBERG, Henry. O Processo da Estratégia. Porto Alegre: Bookman, 2001.

OLIVEIRA, L. M. B. de Remuneração: Estabelecimento e Tendências: Um Estudo nas Empresas do Brasil. Encontro da ANPAD - EnANPAD, 2001.

PICARELLI, V. Filho \& WOOD, T. Junior. Remuneração por habilidades e por competências: preparando a organização para a era das empresas de conhecimento intensivo. São Paulo: Atlas, 1999.

PORTER, M. e.: Vantagem Competitiva: Criando e sustentando um desempenho superior. Campus, Rio de Janeiro, 1990.

REIS-NETO, M. T. A Remuneração Variável na Percepção dos Empregados e suas Consequências na Motivação e no Desempenho. Encontro da ANPAD - EnANPAD, 2006.

RUDIO, F. V. Introdução ao Projeto de Pesquisa Científica. Petrópolis: Vozes, 1999.

STROBEL, J. C. Modelo para Mensuração da Sustentabilidade Corporativa Através de Indicadores. 129 f. Dissertação (Mestrado em Engenharia de Produção). Programa de Pós-Graduação em Engenharia de Produção. UFSC, Florianópolis, 2005.

TRIPODI, T.; FELLIN, P.; MEYER, H. Análise de Pesquisa Social. Rio de Janeiro: Francisco Alves, 1981.

VASCONCElos, K. A. de; SILVA, G. A. V. da A Aplicação da Remuneração Variável: Conectando o Sistema de Recompensas ao Balanced Scorecard. Encontro da ANPAD - EnANPAD, 2007. 
YANADORI, Y.;KANG, S. C. Intra-firm differentiation of compensation systems: evidence from US high-technology firms. Human Resource Management Journal, v.21, n.3, p.236-257. 2011.

cross ref

WOOD, T.; PICARELLI, V. Remuneração estratégica: a nova vantagem competitiva. São Paulo: Atlas, 1996.

\section{Dados dos Autores:}

Nome Completo: Ademar Dutra, Dr.

Filiação Institucional: Universidade do Sul de Santa Catarina - UNISUL

Rua Itararé, 41. Parque São Jorge - Florianópolis - SC, CEP: 88034-470

Telefones para contatos : (48) 3209-1916

Email : cademar.dutra@unisul.br

Nome Completo: Mauro Rodrigues, M.Sc.

Filiação Institucional: Universidade do Sul de Santa Catarina - UNISUL

Rua Santos Saraiva, 1083 - Centro Comercial Ibagy. Estreito Florianópolis - SC, CEP: 88070-101

Telefone para contatos: (48) 2108-8201

Email: mauro.rodrigues@xbramar.com.br

Nome Completo: Fernando Antonio Ribeiro Serra, Dr.

Filiação Institucional: Universidade do Sul de Santa Catarina - UNISUL

Rua Trajano, 219. Centro - Florianópolis - SC, CEP: 88010-010

Telefone para contatos: (48) 8827-7995

Email :fernandoserra@hsm.com.br

Nome Completo: Maurício Vasconcellos Leão Lyrio, M.Sc.

Filiação Institucional: Instituto de Ensino Superior da Grande Florianópolis - IES/GF

Rua Lauro Linhares, 970, apto. 203 - bloco B2. Trindade - Florianópolis - SC, CEP: 88036-001

Telefone para contato: (48) 3209-8605

Email: mauriciovll@gmail.com

Enviado em: 08/06/2011

Aprovado em: 18/05/2012 